\title{
Genetic Variations of Cytokines and Cytokine Receptors in Psoriasis Patients from China
}

\author{
Xiao-Lan Li, ${ }^{1}$ Chun-Feng $W u^{2}{ }^{2}$ and Gui-Sheng $W u^{2}$ \\ ${ }^{1}$ Department of Dermatology and Rheumatology, Affiliated Yan'an Hospital of Kunming Medical College, \\ Kunming, Yunnan 650051, China \\ ${ }^{2}$ State Key Laboratory of Phytochemistry and Plant Resources in West China, Kunming Institute of Botany, \\ The Chinese Academy of Sciences, Kunming, Yunnan 650201, China
}

Correspondence should be addressed to Xiao-Lan Li; lixiaolan96@hotmail.com and Gui-Sheng Wu; wuguisheng@mail.kib.ac.cn Received 20 March 2014; Accepted 11 May 2014; Published 25 May 2014

Academic Editor: Ji-Fu Wei

Copyright (C) 2014 Xiao-Lan Li et al. This is an open access article distributed under the Creative Commons Attribution License, which permits unrestricted use, distribution, and reproduction in any medium, provided the original work is properly cited.

\begin{abstract}
Psoriasis is a chronic inflammatory and hyperproliferative skin disease affected by both genetic and environmental factors. The aim of the present study was to investigate polymorphisms in a candidate gene family of interleukin (IL) in unrelated Chinese patients with psoriasis and control subjects without psoriasis. In this case-control study, 200 unrelated Chinese psoriasis patients and 298 age- and sex-matched control subjects were enrolled. Genomic DNA was prepared from peripheral blood obtained from all psoriasis patients and control subjects. We genotyped seven single-nucleotide polymorphisms (SNPs) in candidate genes of six ILs: IL4, IL10, IL12B, IL13, IL15, and IL23R, which have been shown in the literature to be associated with psoriasis in other ethnic groups. Among the seven SNPs in the six IL genes studied, only the rs3212227 in the IL12B gene was found to be associated with psoriasis at genotypic level in the studied population. The $\mathrm{C} / \mathrm{C}$ genotype in the IL12B gene is a protective factor of psoriasis $(P=0.0218$; OR $=0.51 ; 95 \% \mathrm{CI}: 0.27-0.96)$ in Chinese. Furthermore, the studied Chinese population has extremely low minor allele frequency for IL23R. Together, the data reveal unique genetic patterns in Chinese that may be in part responsible for the lower risk for psoriasis in this population.
\end{abstract}

\section{Introduction}

Psoriasis is an immunologically mediated chronic inflammatory and hyperproliferative skin disease affected by both genetic and environmental factors. The prevalence of psoriasis varied among populations with different genetic backgrounds and habitats, from 3\% in Northern Europe and $2 \%$ in North America and the UK to $0.1-0.3 \%$ in American Indians and East Asia [1,2]. Psoriasis is proposed to be associated with other immune diseases, such as arthritis and Crohn's disease [3]. Initial causative research has identified strong association between psoriasis and the interleukin genes (IL4, IL10, IL12B, IL13, and IL23R) in the northern European from US and UK [4-7]. Furthermore, the SNP rs56245420 in the IL15 gene has been found to be associated with psoriasis in the Chinese Han population but not in any of the UK, German, or US Caucasian populations investigated [8-10], since the minor allele frequency for this SNP and others across IL15 differs quite strikingly between the populations, suggesting heterogeneity in the genetic susceptibility to psoriasis.

In this study, we aimed to determine if psoriasis is associated with six IL genes that have been strongly associated with psoriasis in Europeans but not well studied in Chinese. The seven included SNPs are rs2243250 in the IL4 gene, rs1800872 in the IL10 gene, rs3212227 in the IL12B gene, rs1800925 and rs20541 in the IL13 gene, rs56245420 in the IL15 gene, and rs11209026 in the IL23R gene.

\section{Materials and Methods}

2.1. Study Population. A total of 200 psoriasis patients and 298 healthy controls were recruited in this study (see Table 2). All participants did not suffer from any other diseases and belonged to Han nationality in Yunnan Province, China. The study was performed according to the Helsinki Declaration 


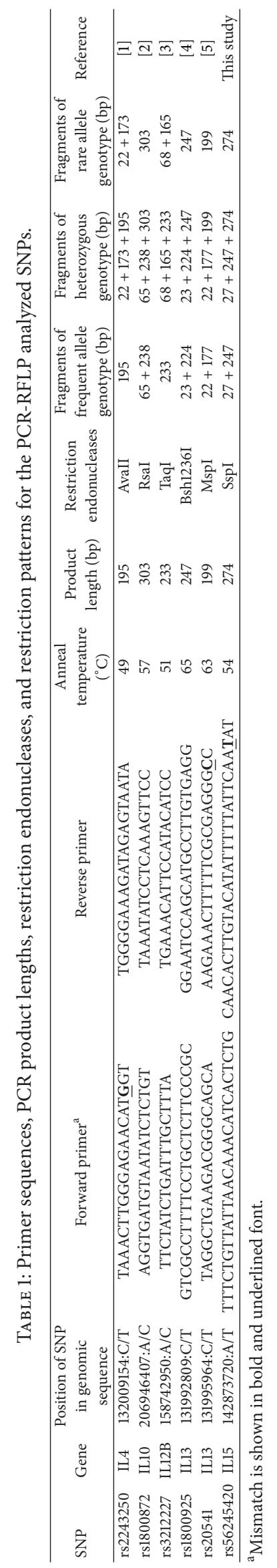


TABLE 2: Genotyping of seven studied SNPs in psoriasis patients $(n=200)$ and controls $(n=298)$.

\begin{tabular}{|c|c|c|c|c|c|c|}
\hline SNP & Gene & Population & & Genotype (\% & & Minor allele (\%) \\
\hline \multirow{3}{*}{ rs 2243250} & \multirow{3}{*}{ IL4 } & & $\mathrm{T} / \mathrm{T}$ & $\mathrm{T} / \mathrm{C}$ & $\mathrm{C} / \mathrm{C}$ & $\mathrm{C}$ \\
\hline & & Controls & $189(63.4)$ & $98(32.9)$ & $11(3.7)$ & $120(20.1)$ \\
\hline & & Psoriasis & $127(63.5)$ & $61(30.5)$ & $12(6.0)$ & $85(21.3)$ \\
\hline \multirow{3}{*}{ rs1800872 } & \multirow{3}{*}{ IL10 } & & $\mathrm{A} / \mathrm{A}$ & $\mathrm{A} / \mathrm{C}$ & $\mathrm{C} / \mathrm{C}$ & $\mathrm{C}$ \\
\hline & & Controls & $138(46.3)$ & $123(41.3)$ & 37 (12.4) & $197(33.1)$ \\
\hline & & Psoriasis & $93(46.5)$ & $86(43.0)$ & $21(10.5)$ & $128(32.0)$ \\
\hline \multirow{3}{*}{ rs3212227 } & \multirow{3}{*}{ IL12B } & & $\mathrm{A} / \mathrm{A}$ & $\mathrm{A} / \mathrm{C}$ & $\mathrm{C} / \mathrm{C}$ & $\mathrm{C}$ \\
\hline & & Controls & 119 (39.9) & $128(43.0)$ & $51(17.1)$ & $230(38.6)$ \\
\hline & & Psoriasis & $77(38.5)$ & $104(52.0)$ & $19(9.5)^{* a}$ & $142(35.5)$ \\
\hline \multirow{3}{*}{ rs1800925 } & \multirow{3}{*}{ IL13 } & & $\mathrm{C} / \mathrm{C}$ & $\mathrm{C} / \mathrm{T}$ & $\mathrm{T} / \mathrm{T}$ & $\mathrm{T}$ \\
\hline & & Controls & $222(74.5)$ & $72(24.2)$ & $4(1.3)$ & $80(13.4)$ \\
\hline & & Psoriasis & $140(70.0)$ & $52(26.0)$ & $8(4.0)$ & $68(17.0)$ \\
\hline \multirow{3}{*}{ rs20541 } & \multirow{3}{*}{ IL13 } & & $\mathrm{C} / \mathrm{C}$ & $\mathrm{C} / \mathrm{T}$ & $\mathrm{T} / \mathrm{T}$ & $\mathrm{T}$ \\
\hline & & Controls & $146(49.0)$ & $126(42.3)$ & $26(8.7)$ & 178 (29.9) \\
\hline & & Psoriasis & $100(50.0)$ & $80(40.0)$ & $20(10.0)$ & $120(30.0)$ \\
\hline \multirow{3}{*}{ rs56245420 } & \multirow{3}{*}{ IL15 } & & $\mathrm{A} / \mathrm{A}$ & $\mathrm{A} / \mathrm{T}$ & $\mathrm{T} / \mathrm{T}$ & $\mathrm{T}$ \\
\hline & & Controls & $139(46.6)$ & $135(45.3)$ & $24(8.1)$ & $183(30.7)$ \\
\hline & & Psoriasis & $78(39.0)$ & $97(48.5)$ & $25(12.5)$ & $147(36.8)$ \\
\hline \multirow{3}{*}{ rs11209026 } & \multirow{3}{*}{ IL23R } & & $\mathrm{G} / \mathrm{G}$ & G/A & $\mathrm{A} / \mathrm{A}$ & $\mathrm{A}$ \\
\hline & & Controls & $298(100)$ & 0 & 0 & 0 \\
\hline & & Psoriasis & $200(100)$ & 0 & 0 & 0 \\
\hline
\end{tabular}

${ }^{* \mathrm{a}} P=0.0218$

with approval of the institutional review boards of the Affiliated Yan'an Hospital of Kunming Medical College and the Kunming Institute of Botany. Informed consent was obtained from each participant before inclusion in this study.

2.2. Determination of Genotype. Genomic DNAs were isolated from whole blood using regular phenol/chloroform method. The SNP rs11209026 in the IL23R gene was genotyped by the TaqMan allelic discrimination method (Applied Biosystems). New PCR-RFLP methods were generated to genotype the SNP rs56245420 in the IL15 gene. Primers $5^{\prime}$ TTTCTGTTATTAACAAACATCACTCTG- $3^{\prime}$ and $5^{\prime}$-CAA CAC TTG TAC ATA TTT TTA TTC AAt AT-3' (mismatch is shown in bold lower case) were used for rs56245420. Other five SNPs were genotyped by PCR-RFLP methods described previously with slight modification [11-15]. PCR reaction was carried out in a total volume of $20 \mu \mathrm{L}$ containing $20 \mathrm{ng}$ of genomic DNA, $1 \times$ PCR buffer, $1.5 \mathrm{mM} \mathrm{MgCl}_{2}, 200 \mu \mathrm{M}$ of each dNTP, $30 \mathrm{ng}$ of each primer, and 1 unit of Taq DNA polymerase (TakaRa). Samples were denatured at $95^{\circ} \mathrm{C}$ for $2 \mathrm{~min}$ followed by 30 cycles of $94^{\circ} \mathrm{C}$ for $45 \mathrm{sec}, 61^{\circ} \mathrm{C}$ (rs2395029) or $54^{\circ} \mathrm{C}$ (rs56245420) for $45 \mathrm{sec}$, and $72^{\circ} \mathrm{C}$ for $45 \mathrm{sec}$ and ended with a final extension for $7 \mathrm{~min}$ at $72^{\circ} \mathrm{C}$. PCR products were digested with $4 \mathrm{U}$ of appropriate restriction endonuclease and electrophoresed on 3\% agarose gels and stained with ethidium bromide. The restriction endonucleases, PCR product lengths, and restriction patterns are shown in Table 1.
2.3. Data Analysis. Statistics analysis was performed by SPSS software for windows (SPSS Inc.). The frequencies of genotypes and alleles for all the six studied loci were determined assuming codominant inheritance. The Hardy-Weinberg equilibrium (HWE) for six loci in psoriasis patients and controls was tested by means of chi-square tests. The statistical significance of the genotype and allele frequency variables between the psoriasis patients and control group was evaluated by chi-square test with Yates correction for small numbers. Relative risk associated with the significant genotype was estimated by the odds ratio (OR). OR with $95 \%$ confidence intervals (95\% CI) was tested using a chi-square distribution and the null hypothesis being tested is $\mathrm{OR}=1 . P$ values $<0.05$ were considered as statistically significant.

\section{Results}

Only one of the fourteen Hardy-Weinberg tests (seven polymorphic loci each in the psoriasis patient and control groups) had $P$ values smaller than $0.05(P=0.01$ at $\mathrm{rs} 3212227$ in controls). All nine remaining genotype frequencies fit Hardy-Weinberg expectations according to chi-square tests in psoriasis patients and controls $(P>0.05)$. Therefore, there is no meaningful deviation from $\mathrm{WHE}$, and our population is derived from random mating.

Polymorphism (minor allele frequency > 1\%) has been found for all studied SNPs except for rs11209026 in the IL23R gene (Table 2). Table 2 shows that rs3212227 in the IL12B gene 
TABLE 3: Correlation of psoriasis symptoms with SNPs in the IL genes.

\begin{tabular}{|c|c|c|c|c|c|c|c|c|}
\hline SNP & Genotype & Psoriasis & Controls & OR $(95 \% \mathrm{CI})$ & Allele & Psoriasis & Controls & OR (95\% CI) \\
\hline \multirow{4}{*}{ rs2243250 } & TT & 127 & 189 & & $\mathrm{~T}$ & 315 & 476 & \\
\hline & TC & 61 & 98 & $0.93(0.63-1.37)$ & $\mathrm{C}$ & 85 & 120 & $1.07(0.78-1.46)$ \\
\hline & $\mathrm{CC}$ & 12 & 11 & $1.62(0.69-3.78)$ & & & & \\
\hline & TC-CC & 73 & 109 & $1.00(0.69-1.45)$ & & & & \\
\hline \multirow{4}{*}{ rs1800872 } & AA & 93 & 138 & & $\mathrm{~A}$ & 272 & 399 & \\
\hline & $\mathrm{AC}$ & 86 & 123 & $1.04(0.71-1.52)$ & $\mathrm{C}$ & 128 & 197 & $0.95(0.72-1.25)$ \\
\hline & $\mathrm{CC}$ & 21 & 37 & $0.84(0.46-1.53)$ & & & & \\
\hline & AC-CC & 107 & 160 & $0.99(0.69-1.42)$ & & & & \\
\hline \multirow{4}{*}{ rs3212227 } & $\mathrm{CC}$ & 19 & 51 & & $\mathrm{C}$ & 142 & 230 & \\
\hline & $\mathrm{AC}$ & 104 & 128 & $2.18(1.21-3.92)$ & A & 258 & 366 & $1.14(0.88-1.48)$ \\
\hline & AA & 77 & 119 & $1.71(0.96-3.17)$ & & & & \\
\hline & AC-AA & 181 & 247 & $1.97(1.12-3.45)$ & & & & \\
\hline \multirow{4}{*}{ rs1800925 } & $\mathrm{CC}$ & 140 & 222 & & $\mathrm{C}$ & 332 & 516 & \\
\hline & $\mathrm{CT}$ & 52 & 72 & $1.15(0.76-1.74)$ & $\mathrm{T}$ & 68 & 80 & $1.32(0.93-1.86)$ \\
\hline & $\mathrm{TT}$ & 8 & 4 & $3.17(0.94-10.72)$ & & & & \\
\hline & CT-CC & 60 & 76 & $1.25(0.84-1.86)$ & & & & \\
\hline \multirow{4}{*}{ rs20541 } & $\mathrm{CC}$ & 100 & 146 & & $\mathrm{C}$ & 280 & 418 & \\
\hline & $\mathrm{CT}$ & 80 & 126 & $0.93(0.64-1.36)$ & $\mathrm{T}$ & 120 & 178 & $1.01(0.77-1.33)$ \\
\hline & $\mathrm{TT}$ & 20 & 26 & $1.12(0.59-2.12)$ & & & & \\
\hline & CT-TT & 100 & 152 & $0.96(0.67-1.37)$ & & & & \\
\hline \multirow{4}{*}{ rs56245420 } & $\mathrm{AA}$ & 78 & 139 & & A & 253 & 413 & \\
\hline & AT & 97 & 135 & $1.28(0.87-1.87)$ & $\mathrm{T}$ & 147 & 183 & $1.28(1.00-1.71)$ \\
\hline & $\mathrm{TT}$ & 25 & 24 & $1.85(0.99-3.46)$ & & & & \\
\hline & AT-TT & 122 & 159 & $1.36(0.94-1.96)$ & & & & \\
\hline
\end{tabular}

$(P=0.0218)$ was associated with psoriasis at genotypic level in the studied population. Other SNPs examined were not associated with psoriasis considered from single locus. As shown in Table 3, while the A/C genotype (OR $=1.48 ; 95 \%$ CI: $0.95-2.30)$ and the alleles (OR $=0.84$; 95\% CI: $0.63-1.13$ ) at rs3212227 in the IL12B were not a risk factor of psoriasis, the $\mathrm{C} / \mathrm{C}$ genotype was a protective factor of psoriasis $(\mathrm{OR}=$ 0.51; 95\% CI: 0.27-0.96).

\section{Discussion}

The etiology of psoriasis is a complex interaction of environmental and biological factors. Genetic factors may play a significant role in the risk of psoriasis in Chinese $[10,16]$. Recent genetic studies indicate that the location of these genes varies considerably among populations and families. We are interested to know if psoriasis is associated with the genes that have been strongly associated with psoriasis in Europeans but not well studied in Chinese.

Our results showed that the IL12B gene was associated with psoriasis in Chinese at genotypic level $(P<0.05)$, which is in line with the findings from European studies [17]. The $\mathrm{C} / \mathrm{C}$ genotype for rs3212227 in IL12B is a protective factor $(\mathrm{OR}=0.51)$ from psoriasis. Similar result from studying SNP rs6887695 in IL12B showed that the minor allele C was a protective factor from psoriasis [5].
The nonsynonymous SNP in IL23R, rs11209026, widely thought to be the primary psoriasis-associated SNP in IL23R in Europeans, was found not to be polymorphic in Chinese, which is in agreement with the findings of others [18]. The low frequencies of variant in IL23R are accordingly of low risk for psoriasis in Chinese. With single SNP analysis, no association is found between the psoriasis and the IL4, IL10, IL13, and IL15 genes.

\section{Conflict of Interests}

The authors declare that there is no conflict of interests regarding the publication of this paper.

\section{Acknowledgments}

This work was supported by Grants from the National Natural Science Foundation of China (81360457) and the Natural Science Foundation of Yunnan Province (2012FB099).

\section{References}

[1] J. E. Gudjonsson and J. T. Elder, "Psoriasis: epidemiology," Clinics in Dermatology, vol. 25, no. 6, pp. 535-546, 2007.

[2] R. Parisi, D. P. Symmons, C. E. Griffiths, and D. M. Ashcroft, "Global epidemiology of psoriasis: a systematic review of 
incidence and prevalence," Journal of Investigative Dermatology, vol. 133, no. 2, pp. 377-385, 2013.

[3] R. P. Nair, T. Henseler, S. Jenisch et al., "Evidence for two psoriasis susceptibility loci (HLA and 17q) and two novel candidate regions (16q and 20p) by genome-wide scan," Human Molecular Genetics, vol. 6, no. 8, pp. 1349-1356, 1997.

[4] K. C. Duffin and G. G. Krueger, "Genetic variations in cytokines and cytokine receptors associated with psoriasis found by genome-wide association," Journal of Investigative Dermatology, vol. 129, no. 4, pp. 827-833, 2009.

[5] Y. Liu, C. Helms, W. Liao et al., "A genome-wide association study of psoriasis and psoriatic arthritis identifies new disease loci," PLoS Genetics, vol. 4, no. 3, 2008.

[6] R. P. Nair, K. C. Duffin, C. Helms et al., "Genome-wide scan reveals association of psoriasis with IL- 23 and NF- $\kappa$ B pathways," Nature Genetics, vol. 41, no. 2, pp. 199-204, 2009.

[7] F. Capon, M. J. Bijlmakers, N. Wolf et al., "Identification of ZNF313/RNF114 as a novel psoriasis susceptibility gene," Human Molecular Genetics, vol. 17, no. 13, pp. 1938-1945, 2008.

[8] R. L. Smith, S. Eyre, R. B. Warren, H. S. Young, C. E. M. Griffiths, and J. Worthington, "No association between polymorphisms in the interleukin-15 gene and early-onset psoriasis in a UK cohort suggests heterogeneity for this susceptibility locus identified in Chinese psoriasis patients," Journal of Investigative Dermatology, vol. 128, no. 12, pp. 2904-2905, 2008.

[9] W. Weger, A. Hofer, P. Wolf et al., "Role of the interleukin $1596516 \mathrm{~A}>\mathrm{T}$ and IL15 96330C $>\mathrm{A}$ gene polymorphisms in caucasian patients with chronic plaque psoriasis," Journal of Dermatological Science, vol. 51, no. 2, pp. 147-149, 2008.

[10] X. J. Zhang, K. L. Yan, Z. M. Wang et al., "Polymorphisms in interleukin-15 gene on chromosome $4 \mathrm{q} 31.2$ are associated with psoriasis vulgaris in Chinese population," Journal of Investigative Dermatology, vol. 127, no. 11, pp. 2544-2551, 2007.

[11] E. Tarazona-Santos and S. A. Tishkoff, "Divergent patterns of linkage disequilibrium and haplotype structure across global populations at the interleukin-13 (IL13) locus," Genes and Immunity, vol. 6, no. 1, pp. 53-65, 2005.

[12] P. E. Graves, M. Kabesch, M. Halonen et al., "A cluster of seven tightly linked polymorphisms in the IL-13 gene is associated with total serum IgE levels in three populations of white children," Journal of Allergy and Clinical Immunology, vol. 105, no. 3, pp. 506-513, 2000.

[13] T. Kawashima, E. Noguchi, T. Arinami et al., "Linkage and association of an interleukin 4 gene polymorphism with atopic dermatitis in Japanese families," Journal of Medical Genetics, vol. 35, no. 6, pp. 502-504, 1998.

[14] C. C. Mok, J. S. Lanchbury, D. W. Chan, and C. S. Lau, "Interleukin-10 promoter polymorphisms in Southern Chinese patients with systemic lupus erythematosus," Arthritis and Rheumatology, vol. 41, no. 6, pp. 1090-1095, 1998.

[15] A. Alvarado-Navarro, M. Montoya-Buelna, J. F. Munoz-Valle, R. I. Lopez-Roa, C. Guillen-Vargas, and M. Fafutis-Morris, "The 3/UTR $1188 \mathrm{~A} / \mathrm{C}$ polymorphism in the interleukin-12p40 gene (IL-12B) is associated with lepromatous leprosy in the West of Mexico," Immunology Letters, vol. 118, no. 2, pp. 148-151, 2008.

[16] F. Long, C. Sun, D. Deng, X. Zhou, X. P. Li, and Y. P. Zhang, "TNF-238A is associated with juvenile onset psoriasis in patients of Han population in Southwest China," Journal of Dermatological Science, vol. 36, no. 2, pp. 109-111, 2004.

[17] F. Capon, S. Semprini, B. Dallapiccola, and G. Novelli, "Evidence for interaction between psoriasis-susceptibility loci on chromosomes 6p21 and 1q21," The American Journal of Human Genetics, vol. 65, no. 6, pp. 1798-1800, 1999.

[18] S. I. Davidson, X. Wu, Y. Liu et al., "Association of ERAP1, but not IL23R, with ankylosing spondylitis in a Han Chinese population," Arthritis and Rheumatism, vol. 60, no. 11, pp. $3263-$ 3268, 2009. 

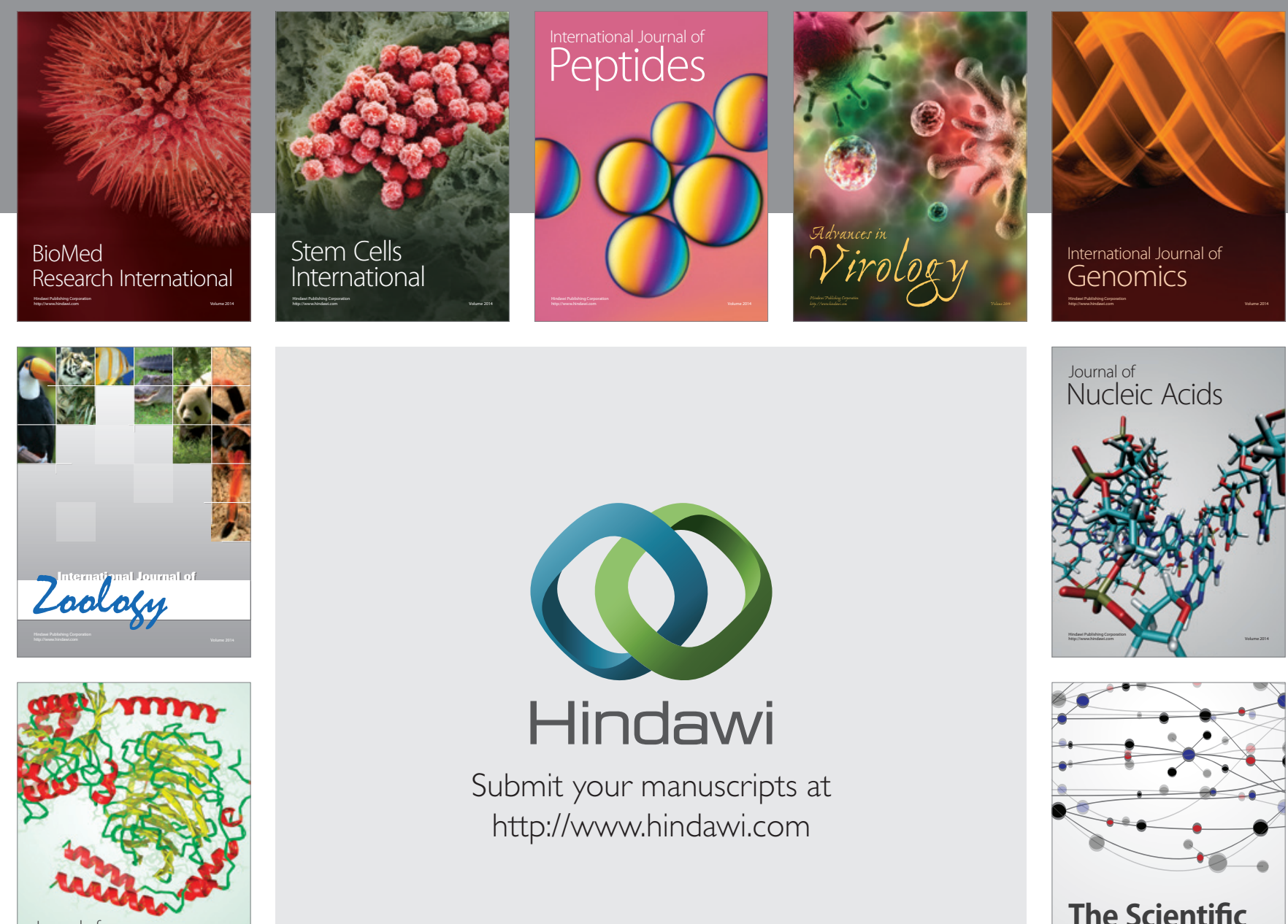

Submit your manuscripts at

http://www.hindawi.com

Journal of
Signal Transduction
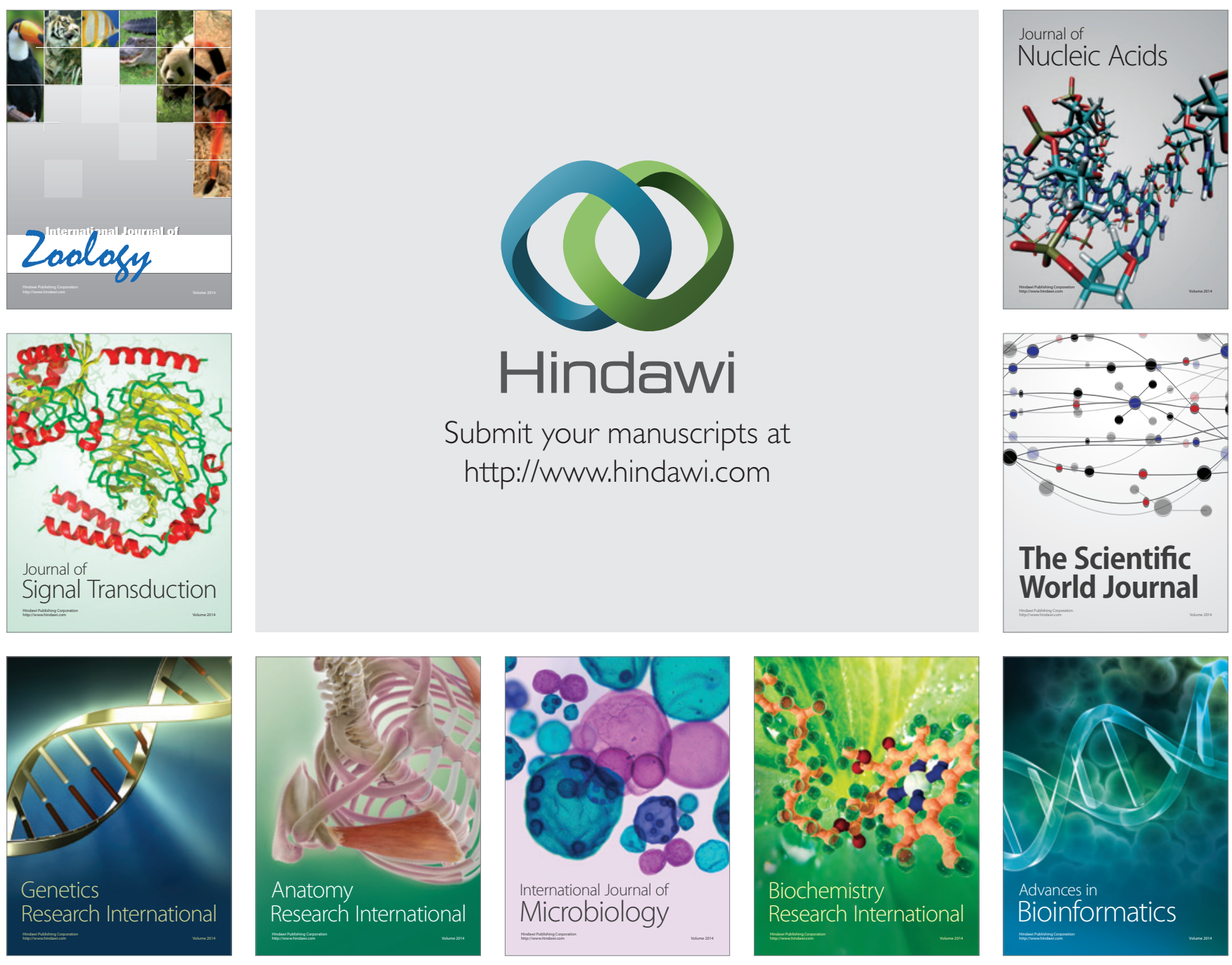

The Scientific World Journal
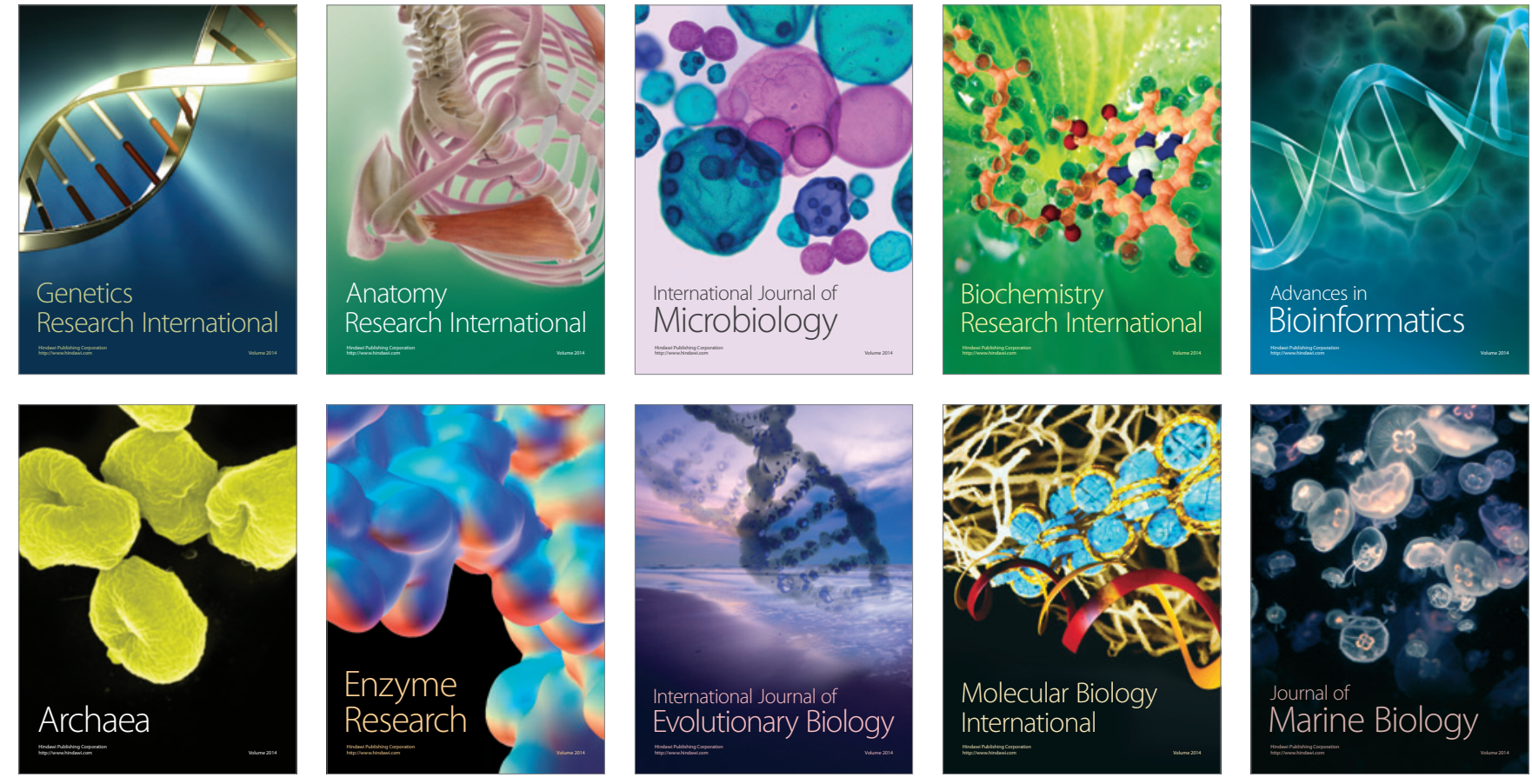